\title{
ENTRE EMÍLIA E MÔNICA: A INFÂNCIA EM EVIDÊNCIA NO DESENHO ANIMADO BRASILEIRO
}

Fernando Teixeira Luiz ${ }^{1}$

${ }^{1}$ Doutor em Letras pela Universidade Estadual Paulista - UNESP. Docente da Universidade do Oeste Paulista UNOESTE, Presidente Prudente, SP. E-mail: fer.luiggi@hotmail.com

\section{RESUMO}

O presente artigo integra uma pesquisa maior, intitulada Poéticas do cinema de animação, desenvolvida entre 2014 e 2015. Tal investigação científica tinha como meta analisar alguns aspectos estéticos e ideológicos de quatro desenhos animados produzidos e comercializados nos últimos setenta anos. Dada a necessidade de recorte do objeto, pretende-se, neste artigo, problematizar somente o processo de representação da criança no desenho animado brasileiro, contemplando um episódio da série $O$ Sítio do picapau Amarelo (2012) e outro da Turma da Mônica (2009). Para tanto, contamos com o apoio dos estudos de Zilberman (1982) acerca dos diferentes modos de abordagem das relações entre adultos e crianças no território da ficção. No que tange à metodologia empregada, optou-se por uma abordagem de natureza qualitativa centrada na análise de documentos, que, no caso, constituem desenhos animados. Em linhas gerais, o estudo sinalizou a presença constante da obra de Maurício de Sousa na história do cinema de animação brasileiro e, no que diz respeito à adaptação da obra de Monteiro Lobato, ressalta-se a projeção de um enredo bastante simplificado se comparado aos livros publicados entre 1921 e 1944, firmando-se como pequenas crônicas do cotidiano das terras de Dona Benta.

Palavras-chave: Desenho animado. Literatura. Infância.

\section{BETWEEN EMIILIA AND MÔNICA: HIGHLIGHTING THE CHILDHOOD IN BRAZILIAN ANIMATED CARTOONS}

\begin{abstract}
This research article is part of a larger research entitled Poetics of animation cinema, developed between 2014 and 2015. The scientific investigation aimed to analyze some aesthetic and ideological elements of four animated cartoons produced and marketed in the last 70 years. Given the need for study delimitation, this article intends to discuss only the process of depiction of children in Brazilian cartoons by covering an episode of the O Sítio do picapau Amarelo (2012) and Turma da Mônica (2009) series. For this, we have the support of Zilberman's (1982) studies on the different ways of approaching relationships between adults and children in the fictional territory. In general terms, the study signals the constant presence of Maurício de Sousa's work in the history of Brazilian animated cinema, and, in regards to the adaptation of Monteiro Lobato's work, it is worth noting the projection of a rather simplified plot when compared to books published between 1921 and 1944.
\end{abstract}

Keywords: Animated cartoons. Literature. Childhood.

ENTRE EMILIA Y MÓNICA: LA INFANCIA EN EVIDENCIA EN EL DISEÑO ANIMADO BRASILEÑO

\section{Resumen}

El presente artículo integra uma gran investigación, intitulada Poéticas del cine de animación, desarrollada entre 2014 y 2015. Tal investigación científica tenía como meta analizar algunos aspectos estéticos e ideológicos de cuatro dibujos animados producidos y comercializados en los últimos setenta años. En este artículo, se pretende problematizar solamente el proceso de representación del niño en el dibujo animado brasileño, contemplando un episodio de la serie O Sítio do Picapau Amarelo (2012) y otro de $A$ Turma da Mônica (2009). Para ello, contamos con el apoyo de los estudios de Zilberman (1982) sobre los diferentes modos de enfoque de las relaciones entre adultos y niños en el territorio de la ficción. En lo que se refiere a 
la metodología empleada, se optó por un enfoque de naturaleza cualitativa centrado en el análisis de documentos, que, en el caso, constituyen dibujos animados. En líneas generales, el estudio señaló la presencia constante de la obra de Maurício de Sousa en la historia del cine de animación brasileño y, en lo que se refiere a la adaptación de la obra de Monteiro Lobato, se resalta la proyección de un enredo bastante simplificado, libros publicados entre 1921 y 1944, firmándose como pequeñas crónicas de lo cotidiano de las tierras de Doña Benta.

Palabras clave: Dibujo animado. Literatura. Infancia.

\section{INTRODUÇÃO}

O presente artigo constitui um recorte de uma pesquisa de pós-doutorado intitulada Poéticas do cinema de animação, desenvolvida, entre 2014 e 2015, na Universidade Estadual Paulista, Campus de Assis. A investigação científica debruçou-se sobre a história do cinema gráfico, analisando quatro produções de diferentes estúdios: Peter Pan (1953), O Natal de Charlie Brow (1965), O Fantástico Mundo de Bobby (1995) e O Sítio do Picapau Amarelo (2012). A análise dos desenhos, articulada à devida contextualização, permitiu delinear a periodização do cinema de animação ao longo do século XX e limiar do século XXI. Em linhas gerais, tal trajetória pode ser dividida em quatro grandes fases: "período de formação, legitimação e consolidação do desenho animado" (1920 1960); "período de desenvolvimento e expansão do mercado" (1960 - 1980); "período das narrativas híbridas" (1960 -1980) e "período da pós-modernidade" (1980 - 2015). As mencionadas categorias não tinham a pretensão de esgotar as nuances que envolvem cada época, mas auxiliar a leitura de diferentes núcleos de desenhos a partir do agrupamento das obras por traços similares. Como seria inviável contemplar todas as etapas aqui descritas, pretende-se, no artigo, abordar apenas um tópico da terceira e da quarta fase, quando as produtoras brasileiras optaram por investir em um mercado proeminente.

Desse modo, em razão da necessidade de recorte do objeto, este artigo tem o objetivo de discutir o processo de representação da criança no cinema gráfico nacional. Para tanto, considera a contribuição de Maurício de Sousa no processo de delineamento do mercado cinematográfico do Brasil mediante a adaptação dos quadrinhos para a linguagem da animação. Nesse contexto, ganhava força, tanto no mercado europeu quanto no norte-americano, a incidência de personagens crianças portadoras de um sólido discurso de autoafirmação. Tal dado refletia, de modo acentuado, as poéticas que igualmente embasavam a literatura infantojuvenil moderna sobretudo com Lewis Carroll e James Barrie - e tinham como precursora, no cenário brasileiro, a figura de Monteiro Lobato.

Considerando o painel que se configurou mediante as informações preliminares apresentadas, o exposto artigo encontra-se dividido em três partes: método, resultados $e$ discussão. $\mathrm{Na}$ primeira, fixa-se nos procedimentos teórico-metodológicos que sustentam a investigação científica, explicitando as diretrizes que justificam e orientam a análise de uma obra de Monteiro Lobato e outra de Maurício de Sousa. Na segunda, insiste, por meio de uma perspectiva historicista, em abordar o itinerário do cinema de animação no Brasil, marcado, sobretudo, pelo trabalho do criador de Mônica e toda a galeria de personagens infantis. Uma vez contextualizadas as bases do desenho animado no território nacional, examina um episódio de duas das séries de maior repercussão na história do cinema infantil brasileiro - $O$ Sítio do Picapau Amarelo (2012) e A Turma da Mônica (2009) - perscrutando o papel da personagem criança na adaptação de uma narrativa já consagrada na historiografia da literatura infantojuvenil e das revistas em quadrinhos.

\section{MÉTODOS}

O proposto artigo, resultado de uma investigação científica de natureza qualitativa, apoia-se na análise documental. Para Severino (2007), a mencionada modalidade de pesquisa abarca uma concepção ampla de documentos, abrangendo poemas, textos narrativos, cartas, produções visuais e obras cinematográficas. Desse modo, não se fixaria em materiais impressos, mas, em larga escala, em "outros tipos de documentos, tais como jornais, fotos, filmes, gravações, documentos legais. Nesses casos, os conteúdos dos textos que ainda não tiveram 
nenhum tratamento analítico, são matéria prima a partir da qual o pesquisador vai desenvolver sua investigação e análise" (p.123).

No caso, temos em evidencia dois desenhos animados (uma adaptação da obra $O$ Sítio do Picapau Amarelo e outra da Turma da Mônica), que serão perscrutados à luz da crítica literária contemporânea e nas concepções debatidas por Zilberman (1982) a respeito dos três grandes modelos familiares: o eufórico, o crítico e o emancipatório. O primeiro, o modelo eufórico (p. 88), centra-se em valores do cotidiano com base em um paradigma adulto dos fatos. Paradigma esse em que a assimetria entre a criança e seus pais ou responsáveis se torna nitidamente acentuada. Aqui, o adulto será sempre representado como uma figura exemplar, detentora do saber, disseminando seus propósitos moralizantes. O segundo, o modelo crítico (p. 90), empenha-se em caracterizar a família como uma instituição em absoluta crise. Desmistifica-se, assim, a imagem do adulto até então atrelada à ideia de uma aura mediadora, denunciando, a partir de agora, a vida doméstica como espaço de preconceito e intolerância. Em última análise, Zilberman explica o modelo emancipador (p. 92). As narrativas, recusando a intervenção dos pais na relação entre a criança e a realidade, sublinham, nos pequenos protagonistas, uma posição de autonomia frente às instâncias superiores e tradicionais.

Para melhor caracterizar duas séries dirigidas a tão diferentes plateias, tomamos como referência os estudos de Bamberger (1987), voltados às fases de interesses de leitura. Com base no pesquisador austríaco, sublinhamos aqui os estágios que podem ser descritos como idade dos contos de fadas (06 a 08 anos), idade das histórias ambientais ou da leitura factual (de 09 a 12 anos) e idade das histórias de aventuras (13 a 14 anos). Nesse sentido, o Sítio do Picapau Amarelo e a Turma da Mônica transitam entre a primeira e a terceira fase, dada a incidência do fantástico, a construção de enredos não tão simplificados e a projeção de um leitor implícito apto a perceber toda a carga intertextual e metaficcional diluída nos meandros da narrativa.

\section{RESULTADOS}

A pesquisa sinalizou que o gênero cinematográfico infantojuvenil merece realce, considerando o determinante de que vigora entre 1970 e 2012 - uma diversidade de produções nacionais. Rey (1989) lembra que tal gênero constitui um "filão" muito explorado no mercado contemporâneo, e que, híbrido por natureza, envolve ação, mistério, romance, suspense e fantasia. Análogo a essas observações, é válido o pronunciamento de Machado (1999). Segundo a escritora, uma das grandes marcas da produção infantojuvenil reside no fato de também ser lido e apreciado por crianças e jovens. As HQs, a literatura e as animações se consagram, então, como territórios para públicos heterogêneos, ávidos por uma história que atenda suas expectativas e alargue seus horizontes culturais.

$\mathrm{Na}$ verdade, assinala-se na produção contemporânea uma linha bastante tênue entre o que convencionalmente se destina aos leitores de tenra idade e o que atende às aspirações do público adulto. A maior evidência disso pode ser encontrada em séries como Mega-Liga MTV de VJs Paladinos (2003) e, em especial, Fudêncio (2005). Por outro lado, a estética essencialmente infantil perdurou nas animações assinadas por Maurício de Sousa. Embora as HQs lançadas recentemente pelo renomado cartunista atinjam a um público nada homogêneo em razão das temáticas tratadas (colégio, preconceito, inclusão etc), as animações veiculadas na década de 1980 ainda mantinham um olhar de inocência para com a infância. O mesmo dado vale para o Sítio do Picapau Amarelo. A literatura lobatiana atribuía vez e voz à criança, permitindo com que protagonizasse diversas façanhas por inúmeras regiões. As adaptações, no entanto, não conseguiam atingir a mesma essência inscrita no texto literário lobatiano, pautando-se muito mais em pequenos episódios do cotidiano de Pedrinho e Narizinho pelas terras de Dona Benta. Não existe, é claro, um pacto de fidelidade absoluta no território da adaptação, e tampouco uma obrigatoriedade para tanto, já que a animação constitui outra obra, com especificidades e valor estético que não estão em discussão. O que vale ressaltar é que os episódios optam por caminhos bastante previsíveis, muitas vezes não rompendo com as expectativas do leitor. Revela-se, por meio da prolepse, o já dito, já visto, já codificado.

Sabe-se que tanto o cinema de animação quanto a literatura infantil e juvenil contemporânea são profícuos em elementos como a intertextualidade, a carnavalização ${ }^{1}$, o

\footnotetext{
${ }^{1}$ Procedimento marcado pela subversão das normas, instaurando um confronto entre o oficial e o não oficial, o sagrado e o profano, o popular e o erudito.
} 
humor, o nonsense ${ }^{2}$, a metalinguagem e a plurissignificação ${ }^{3}$, apostando na inserção de heróis ex-cêntricos. A rigor, constituem expressões artísticas marcadas pela dessacralização do adulto, o que, consequentemente, promove a inclusão de crianças cada vez mais emancipadas. Parte significativa desses traços encontrava em Monteiro Lobato, no território nacional, o grande pioneiro. Como sustenta a crítica literária brasileira posterior a 1970 - cabendo aqui citar Yunes (1982), Vasconcellos (1982), Lajolo e Zilberman (1988) e Sandroni (1998) - Lobato foi, no Brasil, o precursor de uma literatura altamente crítica e inovadora, redimensionando as relações verticais instauradas entre adultos e crianças. Se antes sublinhava-se a representação do adulto como sujeito detentor do saber, Emília, Pedrinho e Narizinho, a partir de então, inauguram uma nova concepção de infância avessa ao tradicional incentivo à obediência e aos bons modos (LUIZ, 2009).

Com os desenhos animados contemporâneos, ressalta-se a incorporação desse modelo. Parte substancial das narrativas produzidas fora do Brasil apresentavam crianças como protagonistas, o que pode ser visualizado em títulos como Em busca do vale encantado (1988), Monstros S. A. (2001), Deu a louca na Chapeuzinho (2005), A Casa Monstro (2006), A família do futuro (2007), Mary e Max (2009), A pequena loja de suicídios (2012), Frankenweenie (2012) e ParaNorman (2012). Já no território nacional, as aventuras protagonizadas pela menina Mônica igualmente aderiam a tal perspectiva, visto que os conflitos vivenciados pelas crianças eram solucionados pelas mesmas, independente da mediação do adulto.

Frente a isso, provavelmente uma das séries mais incisivas nessa área ainda seja $O$ Sítio do Picapau Amarelo (2012), adaptado da obra homônima de Monteiro Lobato. Os livros, ambientados em um cenário tipicamente brasileiro, acabavam compondo um espaço eminentemente transreal, onde a fantasia, o nonsense e a intertextualidade se faziam incidentes. A rigor, o sítio, negando a participação de personagens até então incumbidos pela educação formal das crianças, como pais e mães, apostava em uma avó, Dona Benta, sábia e envolvente contadora de histórias, e em uma

\footnotetext{
${ }^{2}$ Ou comumente chamado de lógica do absurdo.

${ }^{3}$ As várias possibilidades de sentido que se agregam ao texto.
}

cozinheira, Tia Nastácia, representante da cultura popular e responsável pelos deliciosos quitutes da casa (LUIZ, 2009). Nesse local, transitavam ainda duas crianças - Pedrinho e Narizinho acompanhadas do Visconde de Sabugosa, um ilustre e requintado sabugo de milho, e de Emília, esperta e intransigente boneca de pano. As relações familiares, orientadas para 0 que Zilberman (1982) determinaria como modelo emancipatório, conferiam absoluta liberdade para que os pequenos protagonistas se embrenhassem nas mais perigosas aventuras, muitas vezes acompanhados pela própria avó, que jamais se colocava como superprotetora, repressora ou punitiva. Tendo em vista tais particularidades, típicas do universo lobatiano, optou-se por analisar um dos episódios da adaptação da série em questão.

Assim, para elaboração da presente análise, selecionou-se o episódio "O Roubo do Pirlimpimpim", centrado na saga de Narizinho e de seu primo em busca do famoso pó. A esse respeito, é oportuno problematizar como as personagens Lúcia e Pedrinho foram reconstruídas, tendo como base os atores da segunda adaptação do Sítio (2001 - 2007). Já Emília, com olhos expressivos e ostentando um visual que mesclava diferentes tons de verde, parecia retomar modelos mais antigos da personagem, possivelmente encontrados na recriação para o universo dos quadrinhos, no final da década de 1970, divulgada pela Editora RGE e comercializada em todo país.

No desenho animado, Pedrinho, sua prima e a implacável boneca deixavam bem claro já ter vivenciado outras experiências com o pó de pirlimpimpim, o que permite inferir que as novas peripécias ocorreram após o que foi vivenciado nos livros publicados entre 1920 e 1944. Carvalho (1984) define o pó de pirlimpimpim como elemento fantástico que se caracterizava como recurso de gratuidade à fantasia, ao espaço mítico, ao mundo da imaginação, à atmosfera povoada por fadas, duendes e gnomos. "Só as crianças exploravam essa dimensão, só a elas cabia viajar por regiões extracartográficas, extraespaciais e extratemporais, e viver os indescritíveis mundos mágicos" (p. 156). É o citado pó, portanto, que conferia à narrativa seu aspecto maravilhoso, possibilitando que as personagens transitassem por realidades dispersas. Constituiria, talvez, uma entre as múltiplas metáforas lobatianas de leitura 
incorporadas tanto na literatura quanto na animação.

$\mathrm{Na}$ verdade, absorvendo um elemento extraído do romance Peter Pan (1902) - o pó mágico - Lobato instaurava um artifício encantado para justificar a presença do fantástico ao longo da obra. Era por meio do pó que as crianças se deslocavam para a Grécia Antiga, para a Alemanha nazista ou para o espaço sideral. Em harmonia com essas viagens, a animação incorporava a representação de um Pedrinho ávido por se lançar até regiões abarrotadas de piratas, uma Narizinho que almejava conhecer o País das Maravilhas e uma Emília que insistia em retornar às áridas e escaldantes terras das Mil e uma Noites.

Tal painel, pleno de referências intertextuais, será alterado quando a faceira boneca anuncia que o pó de pirlimpimpim estava escondido na floresta. Será a Cuca, contudo, quem irá interceptar o mencionado material, prendendo, mais tarde, as crianças em sua gruta e repetindo a mesma estrutura do livro O Saci (1921). Evitando intercalar adultos para salvar o trio - o que reflete a absoluta sintonia com os propósitos lobatianos - a narrativa se concentrará nas estripulias dos jovens reféns para solucionar o impasse. Orientadas pelo modelo emancipador, ganhava força, novamente, o emprego da mesma fórmula outrora incorporada em $O$ Saci: as crianças deveriam enfrentar a temida feiticeira com ares de jacaré. Tanto em $O$ Saci quanto em "O Roubo do Pirlimpimpim", será a astúcia o elemento primordial para a conquista de um desfecho harmonioso. O ilustre duende de uma perna só, que protagonizava o título de 1921, acabava sendo substituído, no atual episódio, por Emília, cuja postura questionadora centralizará a atenção do leitor.

Por outro lado, a ênfase na Cuca como principal antagonista é um dado que corrobora como a série animada foi erigida muito mais à luz dos episódios dirigidos por Geraldo Casé, em décadas anteriores, que na literatura de Lobato. Reitera-se tal assertiva com o pouco apreço que o criador de Emília conferia à bruxa, apresentandoa apenas, na condição de coadjuvante, em O Saci. A adaptação de 1977 parece ter consagrado a mencionada personagem como um ícone da cultura regional e referência ao ambiente do Picapau Amarelo.

No entanto, é no desfecho que a imprevisibilidade que tanto marcou a escritura lobatiana perde força e aproxima a animação de uma narrativa convencional: Emília, Pedrinho e Narizinho descobriam que o verdadeiro pó de pirlimpimpim sempre esteve, de fato, cozinha, e não na floresta, como conjeturavam. Foi o equívoco da boneca de pano que havia gerado a confusão e, consequentemente, todos os transtornos. Logo, a angústia para recuperar o material, frente às intervenções negativas da Cuca, tornava-se desnecessária.

Ademais, vale sublinhar que possivelmente a proposta da presente série esteja em compor pequenas crônicas da atmosfera do Picapau Amarelo, ou seja, quadros de fatos corriqueiros, do cotidiano agitado e da vida permeada de liberdade em que desfrutavam crianças e idosos, bonecos e seres fantásticos, animais falantes e feiticeiras da mata. O tom, muitas vezes, épico das histórias originais, como sugere Os Doze Trabalhos de Hércules (1944), cede espaço para narrativas menores - na linha do curta-metragem - com poucas complicações e preferência por cenas direcionadas às reinações dos netos de Dona Benta. Paralelamente, preservava-se e exaltava-se o ponto de vista dos pequenos aventureiros sobre a realidade como principal plot que movia toda a efabulação. São os jovens Pedrinho e Narizinho que se expõem aos perigos, vencem obstáculos e se afirmam como sujeitos autênticos, responsáveis e, em especial, emancipados.

Em 2009, A Turma da Mônica foi também adaptada para uma série animada. $O$ trabalho foi desenvolvido pela Paramount Television e pela Maurício de Sousa Produções. O processo de releitura dos quadrinhos para a série de TV não destoava da proposta de adaptação do Sítio do Picapau Amarelo, fixando-se na construção de enredos que se aproximariam de crônicas infantis. A estilização das formas, a recorrência às inúmeras possibilidades de cores oferecidas pela palheta e o traço firme, típico dos quadrinhos, acabava sendo preservado na animação. Outro dado que merece destaque é o modelo emancipatório em evidência, firmado nas relações entre adultos e crianças. Assim, a assimetria congênita às produções dessa linha desenvolvidas por adultos e endereçadas às crianças - parece ter sua distância estreitada na animação. Prova disso é que poucos adultos interferem na ação, permitindo com que a voz da criança predomine em toda a diegese. Ressaltase, desse modo, um discurso de autoafirmação do infante, impondo ao destinatário sua condição, suas necessidades específicas e sua 
visão lúdica e crítica acerca dos fatos. O enredo, assim, concentra-se no universo de Mônica e Cebolinha, nas relações de amizade firmadas e nos conflitos salpicados de humor. Diferente de obras mais complexas que the são contemporâneas - como Monstros S. A. (2000), A Casa Monstro (2006) e A Família do Futuro (2007) - a releitura de A Turma da Mônica mantém resquícios de inocência de determinadas revistas em quadrinhos e de algumas outras produções da década de 1980. Além disso, preza por uma certa universalidade no processo de representação do espaço e no delineamento dos impasses que movem as narrativas. Não há, assim, na série elementos locais que caracterizem o ambiente brasileiro, com sua heterogênea arquitetura e sua flora e fauna singular. $O$ que se destaca é a projeção de uma história que poderia acontecer em qualquer lugar, independente do país ou da etnia das personagens.

No episódio adotado - "O poeta da Lanchonete" (2018) - Cebolinha, auxiliado por seu parceiro Cascão, apresenta mais um de seus infalíveis planos contra Mônica. Lança mão, por meio da prolepse, de expectativas que atingem o leitor e o motivam a refletir acerca da eficácia do plano do menino de cabelos espetados, visto que, nos quadrinhos, o garoto sempre fracassava em razão de um ou outro incidente. O que Cebolinha não imaginava é que sua vítima estaria justamente ao lado de Bianca, uma menina arrojada que despertaria sua paixão e arruinaria mais um de seus planos. Diferente da adaptação do Sítio do Picapau Amarelo, em que a presença do fantástico se fazia constante, não há na Turma da Mônica a incorporação de elementos mágicos, nonsense ou alusões intertextuais a contos de fadas, mitos e fábulas. A narrativa parece muito mais uma comédia de costumes, na linha de Martins Pena, envolvendo situações hilárias e plenamente verossímeis atreladas a temáticas da pré-adolescência: amizade, travessuras e descoberta do amor. Assim, ainda que Cebolinha tenha sua participação dedicada às maldades contra Mônica, firmando-se, muitas vezes, como seu grande antagonista, neste episódio o garoto parece muito mais preocupado com a atração que nutre pelo sexo oposto. Desse modo, vale lembrar que as narrativas de Maurício de Sousa sempre tematizaram a rivalidade entre meninos e meninas, aspecto este corriqueiro no universo infantil. Na animação analisada, a polarização cede espaço ao cotidiano do pré-adolescente, com suas paixões platônicas e a necessidade de omitir seus sentimentos da figura amada.

Um aspecto bastante inovador no desenho está na representação de Bianca como uma garota negra. A galeria de personagens de Sousa incorporava, em sua maioria, personagens brancas. Jeremias e Pelezinho destacavam-se como poucos negros de considerável representatividade nos quadrinhos. Bianca, por sua vez, impõe-se como modelo de beleza. É a garota que Mônica convida para a lanchonete e, mais tarde, despertaria o amor de Cebolinha. A imagem da menina, ampliada por meio de um plano de enquadramento (close), acentua seus cabelos encaracolados e os traços afrobrasileiros, o que compõe um traço bastante positivo inscrito no episódio. Na história da animação, inclusive, não são comuns personagens negras de considerável apelo popular, tendo em vista que o mais emblemático ainda seja o longa-metragem francês Kiriku (1998).

O conflito configura-se plenamente no ensejo em que Cebolinha redige, em dois guardanapos, alguns versos apaixonados direcionados a Bianca. O papel, no entanto, acaba parando nas mãos de Mônica, que o utilizaria para comer um lanche. Ciente do perigo que representava a protagonista - e a eminente possibilidade desta apresentar o guardanapo à pequena Bianca, Cebolinha não hesitou em agir. Partiu para a mesa das duas meninas e utilizou de todos os subterfúgios para reaver o guardanapo com os poemas. Sem sucesso, acabava recebendo uma surra de Mônica, em sintonia com os desfechos muitas vezes previsíveis dos quadrinhos. Para sua surpresa e a do leitor real, o poema chegava ao conhecimento da pequena Bianca que, contrariando as expectativas do destinatário, esboçava para Cebolinha um sorriso de ternura e contentamento.

Nota-se, durante o episódio, a participação exclusiva de personagens crianças, como se os roteiristas se empenhassem em alardear, exclusivamente, a supremacia da voz infantil em toda a diegese. $\mathrm{Na}$ verdade, compreende uma necessidade de começar a desestabilizar uma visão "adultocêntrica" da realidade, para elevar a criança a um lugar de hiper-valorização na literatura, no teatro e, em especial, no cinema infantojuvenil.

Fato que também merece uma observação atenta é a composição das personagens secundárias no processo de construção do efeito de comicidade. Cascão, por 
exemplo, recusa participar do mirabolante plano contra Mônica, mas, contraditoriamente, cede aos apelos do amigo assim que tem a oportunidade de solicitar saborosas comidas ao garçom, em plena lanchonete. Além disso, os versos compostos por Cebolinha não são passíveis ao crédito do leitor, visto que, por serem tão banais ("Bianca, Bianquinha/ O amor do Cebolinha"), são apreciados mais por seu aspecto jocoso a que por uma suposta lírica. Mônica, em contrapartida, mantém seu gênio arrebatador, típico dos quadrinhos, em toda a sequência da série. Assim, é a menina, muito mais forte que os meninos, que se sobressai durante todo o quadro. Não há, portanto, uma fragilidade estampada no comportamento da protagonista, mas um ímpeto veemente que move a personagem (que se aproxima, muitas vezes, da ideia de "empoderamento feminino" incidente em produções culturais contemporâneas). Nem mesmo o aspecto intelectual é conferido aos garotos, já que seus planos, tanto nas revistas quanto na releitura para a série animada, fracassam. Independente, porém, da rivalidade entre sexos, o que se acentua, ao longo do desenho, é uma retórica que sublinha a voz da criança, possibilitando com que elementos de seu dia a dia estruturem todo o enredo. Tal "autonomia" (na expressão de Yazle (2009)) conferida ao universo infantil, torna as personagens crianças tão fortes quanto as adultas. No caso de $O$ poeta da lanchonete, ressalta-se, inclusive, a ausência de adultos durante o episódio. Assim, na mesma linha de Charlie Brown e Mafalda, instaura-se um aprofundamento na dinâmica das personagens, emancipadas por natureza, a medida que delineiam seus próprios caminhos, buscam pela própria identidade e vivem a plenitude da infância.

Observa-se, desse modo, como o Sítio do Picapau Amarelo e a Turma da Mônica investem em uma concepção moderna de infância. Ainda que os desenhos não reflitam o dinamismo da literatura lobatiana e tampouco $o$ jogo intertextual e muitas vezes metaficcional dos quadrinhos de Sousa, é a voz da criança que predomina em toda a narrativa.

\section{DISCUSSÃO}

O caso do desenho nacional constitui um tópico especial quando se trata da história da animação. Mello (2011) lembra que foram "necessários mais de cinquenta anos desde a invenção do cinema para que o público infantil merecesse a atenção dos realizadores brasileiros" (p.97). Segundo Moreno (1978), a produção local, iniciada por volta de 1950, abrangia manifestações ainda isoladas e incipientes, dispondo de poucos recursos econômicos. Consequentemente, a ausência de financiamento significava sério obstáculo para sua divulgação. Nessas condições, poucos foram os artistas que conseguiram resistir à falta de investimentos, responsabilizando-se por uma obra versátil e de qualidade. Vivenciando tal contexto e exaltando alguns pioneiros nesse território, Moreno cita, além do seu próprio trabalho como animador, a persistência de Anélio Lattini Filho, Roberto Miller, José Rubens Siqueira e Yppê Nakashima. Tendo em vista as dificuldades de desenvolvimento de um longa-metragem, os desenhistas acabavam se firmando na esfera da publicidade, dedicando-se, quase sempre, ao circuito de vinhetas direcionadas ao merchandising de determinado produto.

Moreno encontrava-se, precisamente, na década de 1970. Logo, seu registro acerca da formação do mercado nacional de cinema de animação deixava transparecer um quadro não muito heterogêneo, com poucos expoentes e que, por conseguinte, culminava no cartunista Maurício de Sousa e seus anúncios publicitários da Cica. O primeiro curta-metragem que o citado artista rubricou, O Natal da Turma da Mônica (1976), tornou-se alvo de expressivo sucesso de audiência. "Realizado no recém-criado estúdio de desenho animado, teve criação coletiva de Maurício, Márcio (que compôs as músicas), Reinaldo, Cortes e Manuel Messias" (MORENO, 1978, p.114). Porém, as dificuldades encontradas para o êxito da obra foram desgastantes. $\mathrm{Na}$ ocasião, a Maurício de Sousa Produções exaltava a popularidade de suas personagens infantis no território dos quadrinhos, alardeadas pela equipe como superiores a Mafalda e Charlie Brown (op cit. p.114). Quando, contudo, estavam em pauta novas propostas de animação, o grupo não conseguia visualizar, no Brasil, condições de sobrevivência do longa-metragem dentro das salas de exibição. Os custos elevados materializavam-se como fator decisivo que, provavelmente, determinaria seu enfraquecimento e posterior ruína. Por isso, a prioridade para os estúdios era ainda a TV e não no cinema, até então monopolizado pelos estúdios Disney. 
Marchiori (2011), situando-se mais de trinta anos após a publicação de Moreno, acrescenta novos dados ao fato. Explica que, com a chegada dos desenhos japoneses ao Brasil, ao final da década de 1970, Maurício de Sousa sentiu que estava perdendo uma fatia no mercado. Ele já dominava o mercado de quadrinhos e, até então, havia lançado um único filme (O Natal da Turma da Mônica (1976)). Criou, assim, a Black \& White \& Color, um estúdio de animação com mais de setenta artistas. Posteriormente, em uma parceria com a Embrafilme, o estúdio lançou seu primeiro longametragem, As Aventuras da Turma da Mônica (1982), nos cinemas. O referido dado acabou se contrapondo às previsões pessimistas, dos anos 1970, acerca das condições de desenvolvimento da indústria de animação no Brasil. Previsões descritas por Moreno e que, de certa forma, representavam a atmosfera não muito amistosa da época.

0 longa-metragem anunciado contemplava, na verdade, a coletânea de quatro histórias da turma da Mônica (um aglomerado de curtas), extraídas diretamente dos quadrinhos. No ano seguinte, 1983, chegava às telas seu segundo filme - A Princesa e o Robô - que, como ocorria com as produções norte-americanas, não abdicava das referências intertextuais ao filme Guerra nas Estrelas (1977). Nesse sentido, o principal antagonista do desenho, Lorde Coelhão, alusão ao vilão Darth Vader, disputava o amor da princesa protagonista com um obstinado robô. Entre as inúmeras complicações geradas, Mônica, Cebolinha, Cascão, Magali e o Anjinho acabavam intervindo no embate contra o adversário, desencadeando toda a aventura.

Ao longo da década, outros desenhos integraram o rol de títulos da nova produtora, como Bicho Papão e Outras Histórias (1986), Mônica e a Sereia do Rio (1987) e A Estrelinha Mágica (1988). Entretanto, alguns filmes, por falta de incentivo financeiro, foram lançados diretamente em VHS. No geral, as histórias não destoavam da estética estadunidense na composição dos desenhos, centradas, basicamente, na aventura e no confronto de forças antagônicas, como se pode observar em toda a engrenagem de $A$ Princesa e o Robô, marcada pela releitura do filme de Steven Spielberg de 1977. A partir de 2009, porém, ressaltam-se as novas adaptações da Turma da Mônica para o desenho animado, com episódios que duravam, em média, sete minutos.
Talvez o maior sucesso do período ainda seja Os Trapalhões no Rabo do Cometa (1985), elaborado, divulgado e comercializado também pela Maurício de Sousa Produções. Na esteira do sucesso da trupe formada por Didi, Dedé, Mussum e Zacarias, que já havia se consagrado tanto no cinema quanto nas séries dominicais, observa-se a construção de uma narrativa igualmente permeada de fantasia, aventura e gags. Melo (2011) explica que, dos mais de noventa filmes infantis de longa-metragem lançados no Brasil de 1950 até 2004, aproximadamente um terço teve como produtor ou mentor a figura de Renato Aragão. Seu humor, assim, inscreve-se na vertente da cultura popular que teve expressão no cinema nacional por meio das chanchadas e de Mazzaropi. Nessa linha, Melo filia o grupo às raízes do circo e às influências de Charles Chaplin, sobretudo na figura do adorável Carlitos.

Em linhas gerais, Os Trapalhões no Rabo do Cometa operava com um traço não muito infantilizado, como se sublinhava na Turma da Mônica. Ao contrário, dava prioridade às caricaturas do quarteto de humoristas brasileiros. O enredo girava em torno dos artifícios de um bruxo que almejava agarrar a mão de Didi para reaver seus grandiosos poderes, pois, no passado, o trapalhão acabara impedindo o vilão de tocar em um triângulo mágico que o tornaria imbatível. A fidelidade ao modelo de animação norte-americana mostrava-se preservada, tanto que, enquanto, na narrativa, desfilava a história da civilização a partir de quadros cômicos que tematizavam a Idade da Pedra, o Império Romano e a Idade Média, fazia-se também referência ao Velho Oeste, período que, para a cultura brasileira, nunca foi significativo.

Ressalta-se nessa época, portanto, a ausência de um espaço fabuloso capaz de traduzir as peculiaridades de seu próprio povo, como ocorre nos quadrinhos do Chico Bento e na literatura brasileira firmada após o advento dos padrões modernistas. Certamente frente à influência dos estúdios Disney, Warner, Marvel, Filmation e Hanna-Barbera, perdurou no cinema gráfico local o apego aos modelos estrangeiros já consolidados entre as crianças brasileiras. Curiosamente, vale lembrar que o nacionalismo comedido, agora negado, chegou a nortear, nos anos 1950, as primeiras manifestações do gênero. Sinfonia Amazônica (1951), de Anélio Lattini, foi a maior evidência disso. A coletânea de relatos folclóricos da região norte, fiel à 
mitologia indígena, foi reconhecida e premiada nos anos seguintes pelo primoroso trabalho de resgate das raízes culturais brasileiras.

Convém citar, também na década de 1980, as vinhetas do Grilo Feliz e sua turma, de expressiva popularidade entre crianças e jovens. Seu criador, o cineasta Walbercy Ribas, fundou em 1966 o estúdio Start Desenhos Animados, dirigindo inúmeros filmes comerciais que the garantiram, inclusive, diversos prêmios. Tanto as personagens de Ribas quanto as de Maurício de Sousa operavam com uma estética próxima do universo infantil, em harmonia com o que já era produzido pela Disney. Talvez a produção mais alternativa da época ainda seja Cassiopeia (1996), de Clóvis Vieira. Direcionada à ficção científica, constituía o primeiro longa-metragem realizado em computadores, antes mesmo das experiências de Hollywood.

Posteriormente, cineastas e cartunistas observaram que o traço menos infantilizado ampliava o horizonte mercadológico, abrangendo um nicho cada vez mais heterogêneo. As novas formas gráficas caricatas e irregulares (como dos Simpsons, por exemplo), em oposição ao requinte da Disney, ganhavam tons ainda mais arrojados nas séries nacionais que eram divulgadas no limiar do século XXI, como MegaLiga MTV de VJs Paladinos (2003) e, sobretudo, Fudêncio (2005). Narrando, este último, as peripécias de um grupo de crianças soturnas e abusando de um repertório lexical pleno de gírias, Fudêncio e sua trupe mostravam-se alternativos e pouco simpáticos. Funérea, uma das protagonistas, tornar-se-ia mais tarde apresentadora de um talk show na MTV. Seu humor corrosivo e os modos pouco cordiais de abordagem dos entrevistados - sempre tripudiando-os - tornava a personagem bastante irreverente e pouco previsível na história da animação. Seu bordão ("infortúnio !!!") constituía um eixo revelador dos aspectos sombrios que ostentava: tinha péssimo humor, propensão por ambientes macabros e composição visual nitidamente sinistra, lembrando, muitas vezes, um duende.

Chegando, finalmente, ao Sítio do Picapau Amarelo e sua respectiva releitura, alguns dados tornaram-se cruciais. Conforme observamos na tese Reinações na Jecatatuásia: aspectos estético-sociológicos da arte segundo Monteiro Lobato (LUIZ, 2009), o texto lobatiano sempre foi marcado por elementos como intertextualidade, metalinguagem, humor ácido e diálogo com o folclore, o conto de fadas, o cinema e a mitologia greco-romana. Não obstante, ressalta-se a imponência de figuras femininas, como Dona Benta, Tia Nastácia, Narizinho e, sobretudo, Emília. Atrelado a tal fator, observa-se a forte visualidade diluída na escritura de Lobato, o que possibilitou com que diferentes ilustradores, nos mais diversos contextos, dialogassem e traduzissem a saga dos habitantes das terras do Picapau Amarelo para a linguagem plástica. Corroborando esse painel, sublinha-se uma expressiva fortuna crítica, materializada em artigos, ensaios, dissertações e teses que versavam sobre as criações fantásticas de Lobato como incontestáveis referências na história da literatura para crianças.

Não foram poucas as adaptações do Sítio para a TV. Em especial, as mais populares acabaram sendo recriações comercializadas pela Rede Globo entre 1977 e 1986, protagonizadas por Zilka Salaberry e Dirce Migliaccio, dirigidas por Geraldo Casé. Entre 2001 e 2007, retomou-se a proposta de Casé, atualizando o Sítio de Dona Benta - com telefones celulares e microcomputadores - e contando com as participações de Nicette Bruno e Isabelle Drummond nos papeis principais. A terceira grande empreitada, a esse respeito, deu-se em 2012, transpondo as aventuras de Pedrinho, Narizinho e Emília para as formas gráficas visuais. O diálogo entre as três adaptações mostrou-se intenso, tendo em vista que sublinhavam a presença do Saci Pererê e da Cuca como temidos antagonistas - aspecto pouco explorado na literatura de Monteiro Lobato e que ganhava novos contornos na TV.

A série animada do Sítio do Picapau Amarelo (2012) foi produzida pelos estúdios 2DLab e Split/ Animatório Content, apresentando as personagens mediante um traço nitidamente infantilizado, mas pleno de cores, luzes e movimentos. Os episódios veiculados, todos, em média, com duração de dez minutos, não eram adaptações de aventuras extraídas das páginas rubricadas por Monteiro Lobato. As sete histórias consultadas - "Um Lugar Diferente", "O Roubo do Pirlimpimpim", "A História do Gato", "A Princesa do Reino das Águas Claras", "O Grande Aventureiro", "A Tarefa do Visconde" e "As Promessas do Rabicó" - formulam-se como novos enredos protagonizados pelos habitantes do mirabolante Sítio.

\section{ENFIM...}


Resta sublinhar que, mesmo aderindo a textos narrativos bastante simplificados no território da animação (se compararmos aos enredos veiculados tanto na literatura quanto nas produções em quadrinhos), nota-se a importante contribuição dos citados títulos no processo de formação do cinema gráfico brasileiro. 0 pioneirismo de Monteiro Lobato e de Maurício de Sousa foram cruciais nesse sentido, oferecendo um farto material para posterior releitura.

Nesse prisma, tanto Mônica quanto Emília caracterizavam vozes não apenas infantis, mas também femininas, capazes de acentuar a representatividade da mulher no espaço da arte. São fortes, destemidas e impávidas, apresentando modos particulares para resolução de conflitos, independente da intervenção do adulto. Logo, ganha espaço um discurso, por meio das práticas das duas personagens, de valorização da criança, na mesma linha de figuras como Mafalda, Clara Luz e Píppi Meialonga.

\section{REFERÊNCIAS}

BAMBERGER, R. Como incentivar o hábito de leitura. São Paulo: Ática, 1987.

BARRIE, J. Peter Pan. Rio de Janeiro: Editora Pequena Zahar, 2013. (primeira edição em 1902)

CARVALHO, B. V. Literatura Infantil: visão histórica e crítica. São Paulo: Global: 1984.

LAJOLO, M.; ZILBERMAN, R. Literatura Infantil Brasileira: História e Histórias. São Paulo: Ática, 1998.

LOBATO, M. Obras Completas. São Paulo: Ed. Brasiliense, 1972 [primeira edição em 1931].

LUIZ, F. T. Reinações na Jecatatuásia: aspectos estético sociológicos da arte segundo Monteiro Lobato. 2009. Tese (Doutorado em Literatura e Vida Social). Faculdade de Ciências e Letras, Universidade Estadual Paulista, Assis.

MACHADO, A. M. Contracorrente: Conversas sobre leitura e literatura. São Paulo: Ática, 1999.

MARCHIORI, E. Tela Grande. Revista Mundo dos Super-Heróis. São Paulo: Editora Europa, 2011.

MELO, J. B. Lanterna Mágica: infância e cinema infantil. Rio de Janeiro: Civilização Brasileira, 2011.
MORENO, A. A experiência brasileira no cinema de animação. São Paulo: Arte Nova, 1978.

REY, M. O roteirista profissional. São Paulo: Ática, 1989.

SANDRONI, L. De Lobato à Década de 70. In: SERRA, E. 30 Anos de Literatura para Crianças e Jovens: Algumas Leituras. São Paulo: Mercado Aberto, 1998.

SEVERINO, A. J. Metodologia do trabalho científico. São Paulo. Cortez, 2007.

VASCONCELLOS, Z. M. C. O universo mágico da obra infantil de Monteiro Lobato. São Paulo: Editora Traço, 1982.

YAZLLE, S. C. L. Vozes da Criança: o discurso de auto-afirmação na literatura infantil de Ana Maria Machado. 2008. Tese (Doutorado em Literatura e Vida Social). Faculdade de Ciências e Letras, Universidade Estadual Paulista.

YUNES, E. Presença de Monteiro Lobato. Rio de Janeiro: Divulgação e Pesquisa, 1982.

ZILBERMAN, R. A Literatura Infantil na Escola. São Paulo: Global Editora, 1982.

\section{ANEXO}

Anexo 1 - Tabela dos filmes citados

\begin{tabular}{|l|l|l|}
\hline $\begin{array}{l}\text { Série/ Longa- } \\
\text { metragem }\end{array}$ & Título & $\begin{array}{l}\text { Autoria/ } \\
\text { Estúdio }\end{array}$ \\
\hline Documentário & $\begin{array}{l}\text { Sinfonia } \\
\text { Amazônica (1951) }\end{array}$ & $\begin{array}{l}\text { Anélio } \\
\text { Lattini Filho }\end{array}$ \\
\hline $\begin{array}{l}\text { Curta- } \\
\text { metragem }\end{array}$ & $\begin{array}{l}\text { O Natal da Turma } \\
\text { da Mônica (1976) }\end{array}$ & $\begin{array}{l}\text { Maurício } \\
\text { de Souza }\end{array}$ \\
\hline $\begin{array}{l}\text { Longa- } \\
\text { metragem }\end{array}$ & $\begin{array}{l}\text { Guerra nas } \\
\text { estrelas (1977) }\end{array}$ & $\begin{array}{l}\text { George } \\
\text { Lucas }\end{array}$ \\
\hline $\begin{array}{l}\text { Longa- } \\
\text { metragem }\end{array}$ & $\begin{array}{l}\text { As aventuras da } \\
\text { Turma da Mônica } \\
\text { (1982) }\end{array}$ & $\begin{array}{l}\text { Maurício } \\
\text { de Souza }\end{array}$ \\
\hline $\begin{array}{l}\text { nga- } \\
\text { metragem }\end{array}$ & $\begin{array}{l}\text { A princesa e o } \\
\text { robô (1983) }\end{array}$ & $\begin{array}{l}\text { Maurício } \\
\text { de Souza }\end{array}$ \\
\hline $\begin{array}{l}\text { Longa- } \\
\text { metragem }\end{array}$ & $\begin{array}{l}\text { Os trapalhões no } \\
\text { rabo do cometa } \\
\text { (1985) }\end{array}$ & $\begin{array}{l}\text { Maurício } \\
\text { de Souza }\end{array}$ \\
\hline $\begin{array}{l}\text { Longa- } \\
\text { metragem }\end{array}$ & $\begin{array}{l}\text { O Bicho Papão e } \\
\text { outras histórias } \\
\text { (1986) }\end{array}$ & $\begin{array}{l}\text { Maurício } \\
\text { de Souza }\end{array}$ \\
\hline
\end{tabular}




\begin{tabular}{|c|c|c|}
\hline $\begin{array}{l}\text { Longa- } \\
\text { metragem }\end{array}$ & $\begin{array}{l}\text { Mônica e a sereia } \\
\text { (1987) }\end{array}$ & $\begin{array}{l}\text { Maurício } \\
\text { de Souza }\end{array}$ \\
\hline $\begin{array}{l}\text { Longa- } \\
\text { metragem }\end{array}$ & $\begin{array}{l}\text { A estrelinha } \\
\text { mágica (1988) }\end{array}$ & $\begin{array}{l}\text { Maurício } \\
\text { de Souza }\end{array}$ \\
\hline $\begin{array}{l}\text { Longa- } \\
\text { metragem }\end{array}$ & $\begin{array}{l}\text { Em busca do vale } \\
\text { encantado (1988) }\end{array}$ & $\begin{array}{l}\text { Universal } \\
\text { Studios }\end{array}$ \\
\hline $\begin{array}{l}\text { Longa- } \\
\text { metragem }\end{array}$ & Cassiopeia (1996) & $\begin{array}{l}\text { Clovis } \\
\text { Vieira }\end{array}$ \\
\hline $\begin{array}{l}\text { Longa- } \\
\text { metragem }\end{array}$ & Kiriku (1998) & Ocelot \\
\hline $\begin{array}{l}\text { Longa- } \\
\text { metragem }\end{array}$ & $\begin{array}{l}\text { Monstros S. A. } \\
\text { (2000) }\end{array}$ & $\begin{array}{l}\text { Pixar/ } \\
\text { Disney }\end{array}$ \\
\hline $\begin{array}{l}\text { Série: Mega- } \\
\text { Liga MTV de } \\
\text { VJs Paladinos } \\
\text { (2003) }\end{array}$ & $\begin{array}{l}\text { O roubo da tocha } \\
\text { olímpica (2003) }\end{array}$ & $\begin{array}{l}\text { Marco } \\
\text { Pavão }\end{array}$ \\
\hline $\begin{array}{l}\text { Série: } \\
\text { Fudêncio } \\
\text { (2005) }\end{array}$ & $\begin{array}{l}\text { Fudêncio mutante } \\
\text { (2005) }\end{array}$ & $\begin{array}{l}\text { Thiago } \\
\text { Martins/ } \\
\text { Marco } \\
\text { Pavão. }\end{array}$ \\
\hline $\begin{array}{l}\text { Longa- } \\
\text { metragem }\end{array}$ & $\begin{array}{l}\text { Deu a Louca na } \\
\text { Chapeuzinho } \\
\text { (2005) }\end{array}$ & $\begin{array}{l}\text { Cory } \\
\text { Edwards }\end{array}$ \\
\hline $\begin{array}{l}\text { Longa- } \\
\text { metragem }\end{array}$ & $\begin{array}{l}\text { A Casa Monstro } \\
(2006)\end{array}$ & $\begin{array}{l}\text { S. Sperlberg } \\
\text { / R. } \\
\text { Zemeckis }\end{array}$ \\
\hline $\begin{array}{l}\text { Longa- } \\
\text { metragem }\end{array}$ & $\begin{array}{l}\text { A família do } \\
\text { futuro (2007) }\end{array}$ & $\begin{array}{l}\text { Walt } \\
\text { Disney }\end{array}$ \\
\hline $\begin{array}{l}\text { Longa- } \\
\text { metragem }\end{array}$ & $\begin{array}{l}\text { Mary e Max } \\
\text { (2009) }\end{array}$ & Adam Elliot \\
\hline $\begin{array}{l}\text { Série: } A \\
\text { Turma da } \\
\text { Mônica (2012) }\end{array}$ & $\begin{array}{l}\text { O poeta da } \\
\text { lanchonete (2018) }\end{array}$ & $\begin{array}{l}\text { Maurício } \\
\text { de Sousa } \\
\text { Produções. }\end{array}$ \\
\hline $\begin{array}{l}\text { Longa- } \\
\text { metragem }\end{array}$ & $\begin{array}{l}\text { A pequena loja de } \\
\text { suicídios (2012) }\end{array}$ & $\begin{array}{l}\text { Patrice } \\
\text { Leconte }\end{array}$ \\
\hline $\begin{array}{l}\text { Série: O Sítio } \\
\text { do Picapau } \\
\text { Amarelo } \\
(2012)\end{array}$ & $\begin{array}{l}\text { O roubo do } \\
\text { pirlimpimpim } \\
\text { (2012) }\end{array}$ & Mixer \\
\hline $\begin{array}{l}\text { Longa- } \\
\text { metragem }\end{array}$ & $\begin{array}{l}\text { Frankenweenie } \\
\text { (2012) }\end{array}$ & Tin Burton \\
\hline $\begin{array}{l}\text { Longa- } \\
\text { metragem }\end{array}$ & $\begin{array}{l}\text { ParaNorman } \\
\text { (2012) }\end{array}$ & Laika \\
\hline
\end{tabular}

Fonte: Autor (2019)

Submetido: $13 / 10 / 2018$

Correções obrigatórias: 28/03/2019

Aceite final: 02/04/2019 